\title{
Bottom of Gingival Sulcus
}

National Cancer Institute

\section{Source}

National Cancer Institute. Bottom of Gingival Sulcus. NCI Thesaurus. Code C94549.

The point at which the gingival sulcus terminates because the tissue attaches directly to the tooth. 